\title{
CONHECIMENTO DOS FONOAUDIÓLOGOS \\ DE PORTO ALEGRE SOBRE A ATUAÇÃO \\ FONOAUDIOLÓGICA NO IMPLANTE COCLEAR
}

\section{The knowledge that speech therapists in Porto Alegre/RS have about the speech therapy care as for the cochlear implant}

\author{
Pricila Sleifer ${ }^{(1)}$, Vanessa Américo Fernandes ${ }^{(2)}$
}

\begin{abstract}
RESUMO
Objetivo: verificar e analisar o conhecimento dos fonoaudiólogos, da cidade de Porto Alegre/RS, sobre a atuação fonoaudiológica no implante coclear, como também, explicitar, por meio de revisão bibliográfica, o que a literatura propõe como competência da Fonoaudiologia na equipe interdisciplinar de implante coclear. Método: 81 fonoaudiólogos atuantes em Porto Alegre/RS, em qualquer área da Fonoaudiologia, participaram da pesquisa respondendo a um questionário contendo 18 (dezoito) questões objetivas de múltipla escolha referente à (às) área (as) em que os participantes atuaram ou atuam, se já haviam sido instruídos durante a graduação sobre a atuação fonoaudiológica no implante coclear, ou se haviam realizado algum curso de extensão, aperfeiçoamento ou especialização sobre tal dispositivo. Além disso, foram questionados sobre a definição de implante coclear, os critérios de indicação de implante coclear, qual a formação necessária para que o profissional de Fonoaudiologia atue na equipe de implante coclear, e qual a sua atuação, se houvesse, nos períodos pré, peri e pósoperatório. Resultados: os fonoaudiólogos pesquisados não apresentam o conhecimento adequado quanto à atuação da Fonoaudiologia na equipe de implante coclear. As alternativas em que houve o maior número de erros completos ou parciais foram aquelas referentes a candidatos ao implante coclear, lado de inserção deste dispositivo, atuação fonoaudiológica no período pré, peri e pós-operatório (ativação dos eletrodos). Conclusão: esta pesquisa permitiu concluir que os fonoaudiólogos pesquisados, atuantes na cidade de Porto Alegre, não têm o conhecimento satisfatório sobre a atuação fonoaudiológica no implante coclear.
\end{abstract}

DESCRITORES: Implante Coclear; Audiologia; Conhecimentos, Atitudes e Prática em Saúde; Competência Profissional; Prática Profissional

\section{INTRODUÇÃO}

A reabilitação auditiva tem por objetivo permitir ao indivíduo surdo readquirir a percepção auditiva através de dispositivos eletrônicos. Tais dispositivos, disponíveis para esse processo, são: o aparelho

(1) Fonoaudióloga; Professora Adjunta da Universidade Federal do Rio Grande do Sul, UFRGS, Porto Alegre, RS; Especialista em Audiologia pelo CFFa e em Fonoaudiologia pela Universidade Federal de Santa Maria; Mestre e Doutora em Ciências Médicas: Pediatria pela Universidade Federal do Rio Grande do Sul.

(2) Fonoaudióloga; Centro Auditivo Telex, Porto Alegre, RS.

Conflito de interesses: inexistente auditivo e o implante coclear. O aparelho auditivo é utilizado para reabilitar perdas auditivas de diversos graus. Entretanto, esse dispositivo apenas amplifica o som, o que exige que o indivíduo possua uma reserva coclear (células ciliadas presentes) capaz de possibilitar a percepção dos sons e da fala com essa amplificação. Nos casos em que a disfunção auditiva é tão significativa, como por exemplo, na perda auditiva sensorioneural severa e/ou profunda, que impossibilita um adequado desempenho auditivo com o aparelho de amplificação sonora, indicase a segunda alternativa para a reabilitação auditiva, o implante coclear ${ }^{1-4}$.

O implante coclear é um dispositivo eletrônico composto por eletrodos implantados na cóclea, 
capaz de transformar essa informação sonora em sinais elétricos e levá-la diretamente ao nervo auditivo e, a partir deste, para o cérebro ${ }^{5,6}$.

O implante coclear é um recurso valioso para indivíduos acometidos por perda auditiva sensorioneural severa ou profunda, pois restaura, parcialmente, a audição, possibilitando uma comunicação sem leitura labial e sinais, permitindo melhor independência, motivação e relacionamento social ${ }^{3,7}$.

Apesar dos benefícios constatados com o uso do implante coclear, deve-se levar em consideração que sua implantação é um procedimento cirúrgico, que como qualquer outro pode trazer complicações. Dentre as complicações cirúrgicas em pacientes implantados estão: paralisia facial, necrose tecidual no leito cirúrgico, extrusão ou mau posicionamento dos eletrodos, presença de zumbido, alterações vestibulares na primeira semana de pós-operatório, fístula liquórica e defeito no componente externo ${ }^{8}$. É importante ressaltar que as complicações cirúrgicas costumam ser muito pouco freqüentes quando o procedimento cirúrgico é realizado por um cirurgião otologista experiente ${ }^{7,9}$.

Em sua estrutura, o implante coclear é composto por alguns componentes responsáveis pelo funcionamento, podendo ser externos (microfone, processador de fala, bobina e fios de transmissão) ou internos (corpo de implante, feixe de eletrodos cocleares e dois eletrodos extracocleares). No implante coclear a informação sonora é processada da seguinte maneira: primeiramente, o som ambiental é captado pelo microfone do compartimento retroauricular e levado através de um cabo para o processador de fala que digitaliza o som em sinais codificados, estes sinais são enviados para a bobina de transmissão, que, por sua vez, os transforma em sinais de radiofreqüência e os envia para o receptor do implante coclear. O receptor é a parte do implante responsável por fornecer o estímulo elétrico necessário que percorrerá o feixe de eletrodos implantados na cóclea, estimulando as fibras nervosas remanescentes no nervo auditivo. Essa informação sonora é, então, enviada ao cérebro através do sistema auditivo para ser entendida ${ }^{1,6-8,10-12}$.

Esse processo de funcionamento do implante coclear é muito rápido e permite que o indivíduo escute os sons no momento de ocorrência desses, ou seja, a informação sonora é processada em microssegundos, permitindo que seu usuário possa detectar e perceber essa informação auditiva instantaneamente ${ }^{1,8,10}$.

É importante considerar que, apesar de o implante coclear ser um recurso nos casos de perda auditiva, em que o acometimento auditivo é extenso, ele não é indicado para todos os indivíduos e, por isso, o candidato ao implante coclear deve submeter-se à avaliação de uma equipe interdisciplinar que irá definir, de acordo com os achados, se o indivíduo está apto ou não para realizar a cirurgia ${ }^{13}$. O Ministério da Saúde, portaria ํㅜ 1.278, de 20 de outubro de 1999, define que a equipe técnica básica, necessária no programa de implante coclear, compreende os seguintes profissionais: otorrinolaringologista, fonoaudiólogo, assistente social e psicólogo. A equipe complementar engloba: neurologista, neuropediatra, geneticista, clínico geral e pediatra ${ }^{14}$.

$\mathrm{O}$ atendimento e a avaliação do candidato ocorrem da seguinte maneira: o médico otorrinolaringologista recebe o candidato para a consulta inicial, em que realiza a avaliação otorrinolaringológica completa, solicitando os exames para a avaliação diagnóstica e exames complementares, como tomografia computadorizada e ressonância magnética; o fonoaudiólogo recebe, então, o candidato, realizando a avaliação audiológica e de linguagem oral, a fim de averiguar se o candidato possui os critérios necessários para a realização do implante; o candidato segue o atendimento com o assistente social, que irá avaliar os aspectos financeiros e socioculturais da família do candidato, fatores importantes na continuidade do processo; após, o candidato consulta com o psicólogo, que irá avaliar seus aspectos emocionais e cognitivos, além dos aspectos emocionais da família, identificando as expectativas desta quanto ao implante coclear e o seu grau de adesão a esse processo, um cuidado necessário para o sucesso da reabilitação auditiva. Ao final das etapas pré-cirúrgicas e cirúrgicas, o candidato retorna para atendimentos periódicos com o fonoaudiólogo, em que fará a ativação e o ajuste dos eletrodos e treinamento das habilidades auditivas para desenvolver a leitura de fala e aquisição de linguagem ${ }^{3,7,8,10,15}$.

A atuação do fonoaudiólogo na equipe de implante coclear é indispensável, tanto na etapa pré-cirúrgica (fornecendo, por meio das avaliações, o parecer fonoaudiológico) como peri (verificando o funcionamento e nível de resposta do implante coclear) e pós-cirúrgica (ativando os eletrodos do implante coclear e promovendo a reabilitação auditiva). Sendo assim, fica claro que não há possibilidade de ser realizada uma cirurgia de implante coclear sem a presença desse profissional ${ }^{10}$.

Tendo em vista que a atuação fonoaudiológica no implante coclear é um assunto atual, pouco abordado durante a graduação em Fonoaudiologia, de conhecimento restrito a uma minoria de profissionais fonoaudiólogos, com poucas obras publicadas na literatura a respeito, justamente pelo trabalho do fonoaudiólogo ser de extrema relevância em todas as etapas desse processo de avaliação e 
reabilitação do implante coclear, o objetivo desta pesquisa foi de verificar, por meio de questionário, o conhecimento dos fonoaudiólogos, da cidade de Porto Alegre/RS, sobre a atuação fonoaudiológica no implante coclear, como também, explicitar, por meio de revisão bibliográfica, o que a literatura propõe como competência da Fonoaudiologia na equipe interdisciplinar de implante coclear.

\section{MÉTODO}

Esta pesquisa tratou-se de um estudo transversal, observacional e contemporâneo, com levantamento de dados obtidos por meio da aplicação de um questionário com fonoaudiólogos atuantes na cidade de Porto Alegre/RS.

$O$ instrumento da pesquisa continha 18 (dezoito) questões objetivas de múltipla escolha, nas quais se questionou sobre a (as) área (as) em que os participantes atuaram ou atuam, se já haviam sido instruídos durante a graduação sobre a atuação fonoaudiológica no implante coclear, ou se haviam realizado algum curso de extensão, aperfeiçoamento ou especialização sobre tal dispositivo. Além disso, foram questionados sobre a definição de implante coclear, os critérios de indicação desse implante, qual a formação necessária para que o profissional de Fonoaudiologia atue na equipe de implante coclear, e qual a sua atuação, se houvesse, nos períodos pré, peri e pós-operatório (Figura 1). Foram incluídos neste estudo os fonoaudiólogos atuantes em Porto Alegre/RS, em qualquer área da Fonoaudiologia, independente do seu ano de graduação, sendo excluídos os profissionais atuantes em outras cidades do Estado do Rio Grande do Sul ou que se recusaram a participar da pesquisa. Assim, a amostra pesquisada foi constituída por 81 fonoaudiólogos selecionados aleatoriamente e convidados a participar do estudo por meio de visitação em seus locais de trabalho. As variáveis encontradas foram: o ano de graduação em Fonoaudiologia, a(s) área(s) de atuação, realização de curso sobre implante coclear ou instrução durante o período de graduação, definição de implante coclear, os candidatos aptos à utilização e critérios de indicação desse dispositivo, formação profissional necessária para um fonoaudiólogo atuar na equipe de implante coclear e a atuação fonoaudiológica no período pré, peri e pós-operatório.

A pesquisa não ofereceu quaisquer riscos aos participantes, que serão beneficiados por esta, em longo prazo, por meio da divulgação do indispensável trabalho da Fonoaudiologia na equipe de implante coclear, proporcionando a possibilidade de maior inserção e especialização dos fonoaudiólogos nessa área.
Os fonoaudiólogos que participaram da pesquisa foram devidamente esclarecidos sobre os propósitos desta, e incluídos os profissionais que concordaram com o Termo de Consentimento Livre e Esclarecido, documento baseado no item IV das Diretrizes e Normas Regulamentadoras para a pesquisa em Saúde, do Conselho Nacional de Saúde (Resolução 196/96), que foi assinado em duas vias, de igual teor, ficando uma em poder do participante da pesquisa e a outra com as pesquisadoras. As pesquisadoras envolvidas na pesquisa comprometeram-se a utilizar os dados levantados nos questionários somente para fins científicos.

A pesquisa foi aprovada pelo Comitê de Ética em Pesquisa do Centro Universitário Metodista IPA, sob protocolo no 113/2008.

Para descrever o perfil da amostra, segundo as variáveis em estudo, foram feitas tabelas de frequência das variáveis categóricas (respostas do questionário de conhecimento), com valores de frequência absoluta (n) e percentual (\%), e estatísticas descritivas da variável contínua (número de acertos do questionário de conhecimento ou nota transformada em escala de 0 a 10 pontos), com valores de média, desvio padrão, valores mínimo e máximo, mediana e quartis.

Para comparar as respostas do questionário entre os anos de graduação foram utilizados os testes Qui-Quadrado e exato de Fisher (para valores esperados menores do que 5), o teste de Mann-Whitney para comparação da nota total do número de acertos entre duas categorias, e o teste de Kruskal-Wallis para comparação da nota total do número de acertos entre as 3 turmas (1984-1995, 1996-1999 e 2000-2008).

O nível de significância adotado para os testes estatísticos foi de $5 \%$, ou seja, $p<0.05$.

\section{RESULTADOS}

Para a realização da pesquisa foram abordados 81 fonoaudiólogos, atuantes na cidade de Porto Alegre/RS, em qualquer área da Fonoaudiologia. Os resultados obtidos que melhor descrevem o conhecimento dessa população sobre a atuação fonoaudiológica no implante coclear estão descritos a seguir.

A Figura 2 mostra de forma geral o percentual de acerto em cada questão respondida pelos fonoaudiólogos pesquisados. Observa-se um predomínio de respostas parcialmente corretas e/ou incorretas nas questões referentes aos candidatos ao implante coclear, lado de inserção do dispositivo, formação necessária para que o fonoaudiólogo atue na equipe, e as etapas desse processo nas quais o fonoaudiólogo atua (pré-operatório, 


\section{QUESTIONÁRIO SOBRE O CONHECIMENTO DOS FONOAUDIÓLOGOS DE PORTO ALEGRE SOBRE A ATUAÇÃO FONOAUDIOLÓGICA NO IMPLANTE COCLEAR:}

Graduação em Fonoaudiologia em (ano):

\section{As questões abaixo podem ter mais de uma alternativa como resposta.}

1. Área da fonoaudiologia em que atua?

( ) voz ( ) fala ( ) linguagem infantil ( ) linguagem adulto ( ) linguagem escrita

( ) audição ( ) motricidade orofacial ( ) estética facial

2. Área da Fonoaudiologia em que já atuou?

( ) voz ( ) fala ( ) linguagem infantil ( ) linguagem adulto ( ) linguagem escrita

( ) audição ( ) motricidade orofacial ( ) estética facial

3. Durante sua graduação foi instruído em algum momento sobre a atuação fonoaudiológica no implante coclear?

( ) $\operatorname{sim}($ ) não

4. Já realizou algum curso de extensão, aperfeiçoamento ou especialização sobre implante coclear?

( ) $\operatorname{sim}($ ) não

5. $O$ que é implante coclear?

( ) um tipo de aparelho de amplificação sonora.

( ) um circuito elétrico que transforma o sons em impulsos elétricos estimulando diretamente o nervo auditivo

( ) um aparelho de amplificação sonora implantado na cóclea que estimula diretamente o nervo auditivo.

( ) um circuito elétrico que amplifica o som estimulando diretamente o nervo auditivo.

( ) é um dispositivo elétrico que estimula diretamente os núcleos cocleares.

( ) não sabe

6. De acordo com o Ministério da Saúde portaria 1.278 de 20 de outubro de 1999, são crianças e adolescentes candidatos ao implante coclear:

( ) aqueles com surdez pré e pós-lingual e menores de 18 anos de idade

( ) aqueles com experiência prévia com aparelho auditivo por pelo menos três meses

( ) aqueles adolescentes com surdez pré-lingual independente do uso de LIBRAS (Língua Brasileira de Sinais)

( ) todas as alternativas estão corretas

( ) não sabe

7. De acordo com o Ministério da Saúde portaria 1.278 de 20 de outubro de 1999, são adultos candidatos ao implante coclear:

( ) aqueles com surdez pré ou pós-lingual, independente da idade

( ) aqueles não beneficiados com o uso do aparelho auditivo

( ) aqueles motivados e com código lingüístico oral já estabelecido

( ) aqueles com surdez pré-lingual reabilitados por método oral, independente da idade

( ) aqueles com surdez pós-lingual, independente do tempo de surdez

( ) não sabe

8. Para que seja realizado o implante coclear o paciente deve ter uma perda auditiva do tipo:
( ) sensorioneural
( ) mista
( ) condutiva
( ) mista e/ou neurossensorial
( ) não sabe

9. Para que seja realizado o implante coclear o paciente deve ter uma perda auditiva de grau:
( ) moderado
( ) severo
( ) profundo
( ) severo e/ou profundo
( ) não sabe

10. Pela portaria 1.278 de 20 de outubro de 1999, o implante coclear é implantado:
( ) bilateralmente
( ) unilateralmente
( ) unilateralmente e/ou bilateralmente
( ) depende do caso
( ) não sabe

11. Para atuar na equipe de implante coclear é necessário que o fonoaudiólogo possua:
( ) três anos de graduação em Fonoaudiologia
( ) pós-graduação na área de Audiologia
( ) curso de especialização em Audiologia
( ) graduação em Fonoaudiologia
( ) curso de aperfeiçoamento em Audiologia
( ) curso de capacitação e treinamento para atuação com usuários de implante coclear 
12. Você acha que o fonoaudiólogo participa da equipe interdisciplinar que realiza a seleção dos candidatos ao implante coclear:
( ) $\operatorname{sim}$
( ) não
( ) não sabe

13. O fonoaudiólogo, no implante coclear, atua:
( ) no pré-operatório
( ) no pós-operatório
( ) durante a cirurgia
( ) pré-operatório, peri-operatório e pós-operatório
( ) na reabilitação auditiva
( ) não sabe

14. No pré-operatório do implante coclear, o fonoaudiólogo:
( ) realiza a avaliação audiológica.
( ) realiza avaliação fonoaudiológica clínica (fala e linguagem).
( ) realiza a triagem que define que candidatos passarão pelos outros profissionais da equipe.
( ) auxilia nos exames de imagens
( ) auxilia com as avaliações realizando parecer fonoaudiológico do candidato
( ) não sabe

15. Durante a cirurgia o fonoaudiólogo:
( ) atua realizando a telemetria neural
( ) atua verificando a impedância dos eletrodos
( ) nesta etapa não atua, ficando a cirurgia em responsabilidade do médico otorrinolaringologista
( ) atua como observador do processo de colocação do implante coclear, a fim de identificar anormalidades no manejo do implante ou nas estruturas envolvidas para sua colocação
( ) realiza a avaliação fonoaudiológica
( ) não sabe

16. No pós-operatório:
( ) o fonoaudiólogo realiza a ativação dos eletrodos imediatamente após a cirurgia.
( ) o fonoaudiólogo aguarda uma semana da realização da cirurgia para ativar os eletrodos.
( ) o fonoaudiólogo aguarda em média 45 dias da realização da cirurgia para ativar os eletrodos.
( )o fonoaudiólogo aguarda em média 75 dias da realização da cirurgia para ativar os eletrodos.
( ) não sabe.

17. Após o implante coclear o fonoaudiólogo atua:
( ) fornecendo apenas informações quanto ao uso e cuidados com o implante coclear
( ) atua somente ativando o implante coclear já que não há mais presença de surdez
( ) não atua visto que após o implante coclear já não há mais a presença de surdez
( ) atua apenas em casos onde não houve melhora na audição
( ) atua realizando programações freqüentes do implante coclear
( ) não sabe

18. O usuário de implante coclear:
( ) realiza normalmente um atendimento com o fonoaudiólogo após o implante.
( ) realiza atendimentos no semestre.
( ) realiza atendimentos periódicos e permanentes com o fonoaudiólogo.
( ) realiza atendimento com o fonoaudiólogo somente quando necessário.
( ) não sabe

Figura 1 - Questionário utilizado na coleta de dados.

peri-operatório e pós-operatório - ativação dos eletrodos). Tal resultado explicita onde residem as dúvidas dos fonoaudiólogos pesquisados quanto à atuação fonoaudiológica no implante coclear. Cabe ressaltar a homogeneidade de respostas corretas e incorretas para a questão sobre definição de implante coclear, fator que explica que há muita dúvida sobre esse assunto, principalmente porque muitos profissionais confundem o implante coclear com outro dispositivo de reabilitação auditiva, o aparelho auditivo.

Nesta pesquisa participaram profissionais com graduação entre os anos de 1984 e 2008. A
Tabela 1 apresenta a comparação das variáveis categóricas e numéricas entre as 3 turmas de ano de graduação (1984-1995, 1996-1999 e 20002008). Os agrupamentos foram feitos para maior poder estatístico nas análises. Observa-se maior média de acertos para o grupo com graduação entre os anos de 2000-2008.

Pelos resultados apresentados nas Figuras $3 \mathrm{e}$ 4 , verifica-se diferença significativa entre as turmas de ano de graduação para as seguintes variáveis: questão 4 "já realizou algum curso de extensão, aperfeiçoamento ou especialização sobre implante coclear" (maior frequência na turma 2000-2008), e 


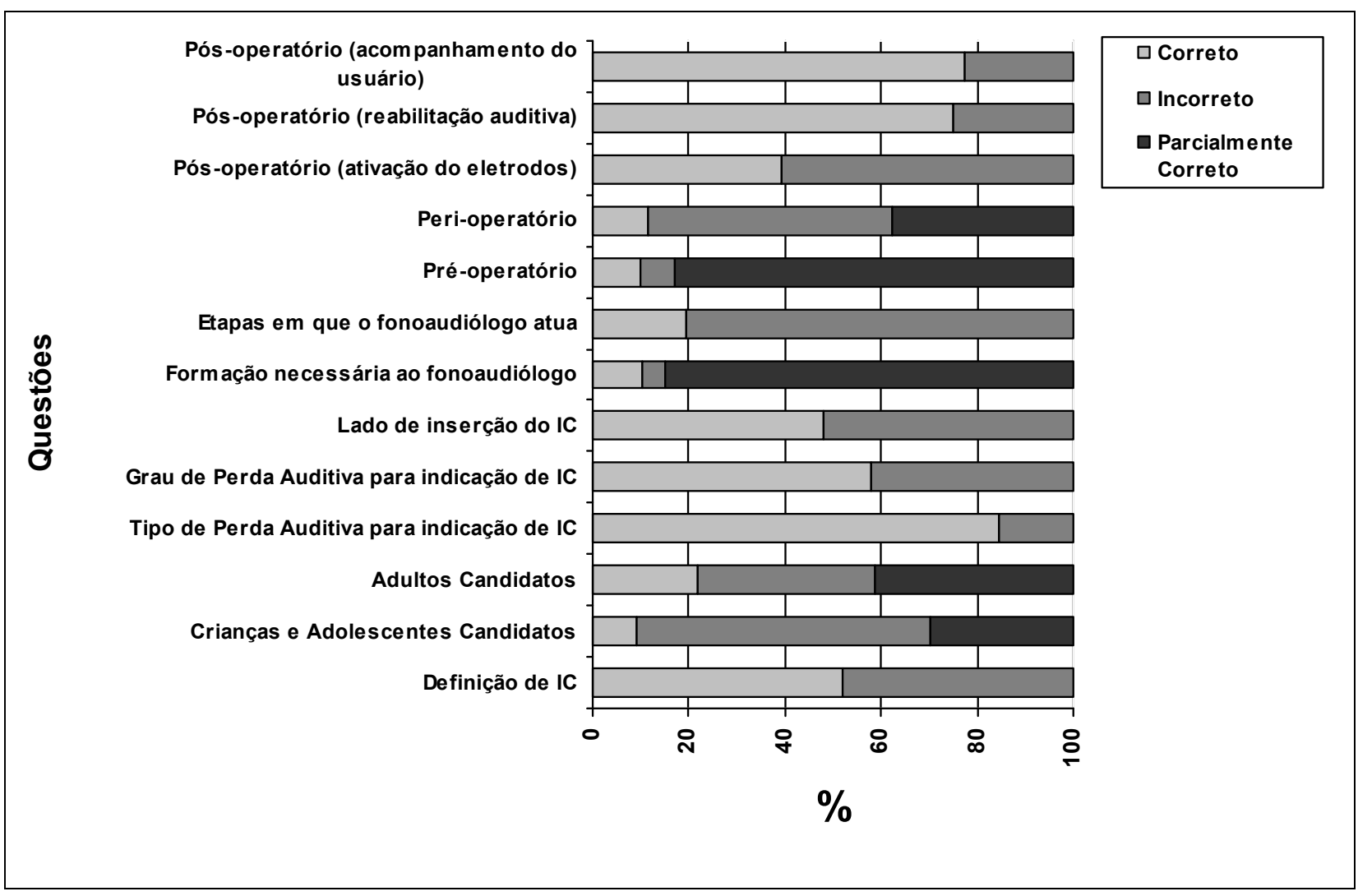

Figura 2 - Percentual de acertos em cada questão

Tabela 1 - Comparação do número total de acertos com o ano de graduação dos fonoaudiólogos pesquisados *

\begin{tabular}{cccc}
\hline Variável & $\mathbf{n}$ & Média $\pm \mathbf{d P}$ & Mediana \\
\hline $1984-1995$ & 13 & $3.82 \pm 2.12$ & 3.85 \\
$1996-1999$ & 23 & $3.96 \pm 1.96$ & 3.85 \\
$2000-2008$ & 28 & $4.85 \pm 2.09$ & 5.19 \\
\hline
\end{tabular}

${ }^{*} \mathrm{n}=17$ excluídos da análise por não-indicação do ano de graduação

Valor $\mathrm{P}=0.100$ teste de Kruskal-Wallis para comparação da variável entre as três turmas

questão 15 "atuação do fonoaudiólogo durante a cirurgia" (maior frequência de parcialmente correto na turma 2000-2008 e de incorreto nas demais turmas).

As Figuras 5, 6 e 7 apresentam as comparações da nota total do número de acertos do questionário, entre as principais variáveis categóricas. Pelos resultados, verifica-se diferença significativa da nota total do questionário para:

- questão 1 - área em que atua (audição), maior nota para os que atuam nesta área;

- questão 2 - área em que atuou (audição), maior nota para os que atuaram nessa área;

- questão 4 - realização de curso de extensão, aperfeiçoamento ou especialização sobre implante coclear, maior nota para os que realizaram curso nessa área.

\section{DISCUSSÃO}

No sul do Brasil, o implante coclear é realizado desde o final da década de $1980^{6}$. Portanto, é um assunto relativamente atual. Provavelmente, devido a esse fato, que a maior média de acertos, quanto à atuação fonoaudiológica no implante coclear, foi do grupo com graduação entre os anos de 2000 e 2008, quando os procedimentos frente ao implante coclear estavam sendo mais conhecidos, desenvolvidos e divulgados. 


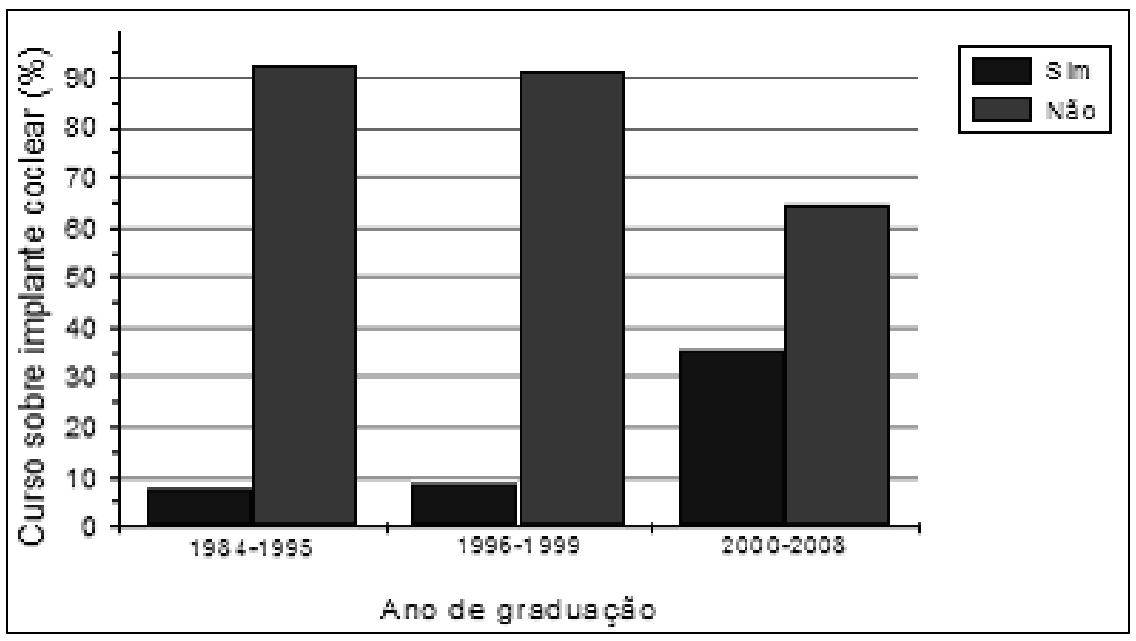

Figura 3 - Comparação entre o ano de graduação dos fonoaudiólogos pesquisados e a realização de curso sobre implante coclear

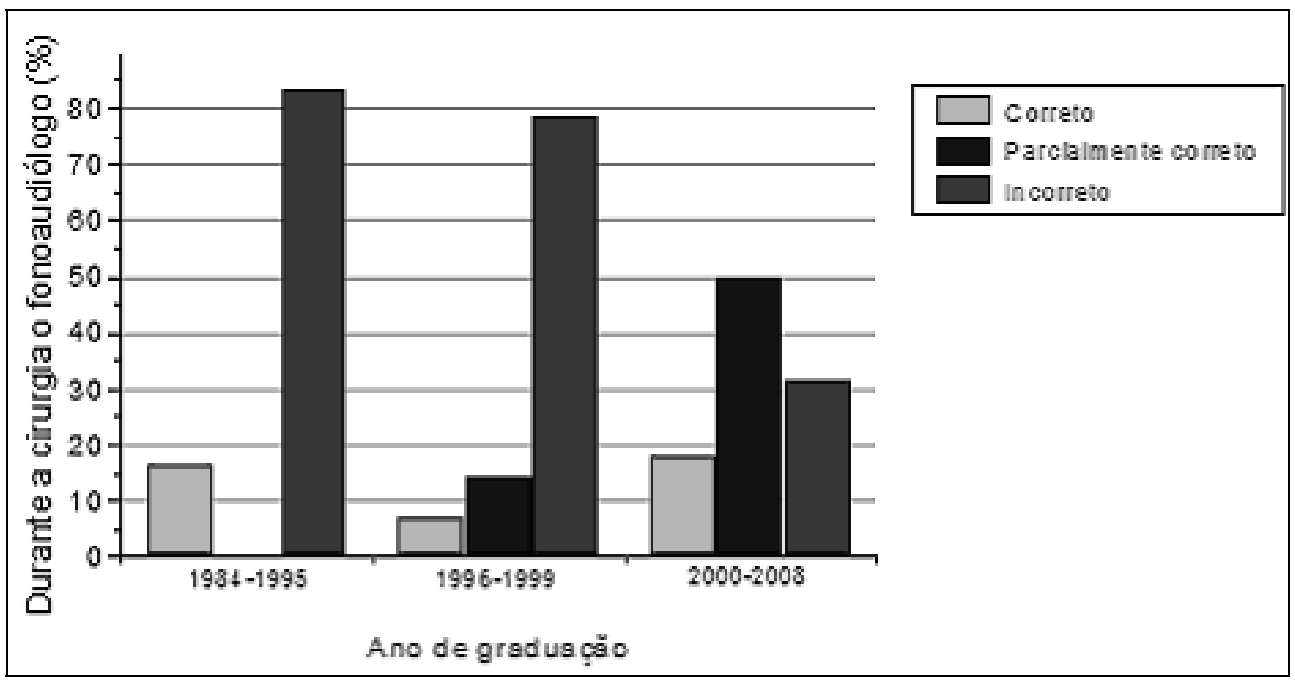

Figura 4 - Comparação entre o ano de graduação dos fonoaudiólogos pesquisados e o conhecimento quanto à atuação do profissional de Fonoaudiologia durante a cirurgia de implante coclear

Outra questão importante é que o número de acertos foi mais significativo para o grupo que atua ou atuou na área da audição (audiologia), ou já havia realizado algum curso de extensão, especialização ou aperfeiçoamento sobre implante coclear (Figuras 5, 6 e 7). Tais achados talvez tenham ocorrido porque o implante coclear é um assunto mais relacionado à área da Audiologia, portanto, os profissionais atuantes nessa área, obtêm mais conhecimento sobre as ações relacionadas a esse dispositivo. Além disso, os fonoaudiólogos que realizaram cursos sobre implante coclear, especificamente, obviamente conhecem e dominam mais esse assunto e as ações a ele pertinentes.
Observou-se que os fonoaudiólogos ainda desconhecem a real definição de implante coclear e como é o seu funcionamento, muitas vezes, confundindo com o aparelho auditivo. O implante coclear é um dispositivo eletrônico composto por eletrodos implantados cirurgicamente na cóclea. É indicado, principalmente, nos casos de perda auditiva sensorioneural profunda, em que há um grande número de células ciliadas lesadas na cóclea, pois o implante coclear tem a capacidade de executar a função dessas células ausentes ou danificadas, estimulando o VIII par craniano e o nervo auditivo. Sua função não é, portanto, amplificar o som, como ocorre com o aparelho auditivo, mas transformar a 


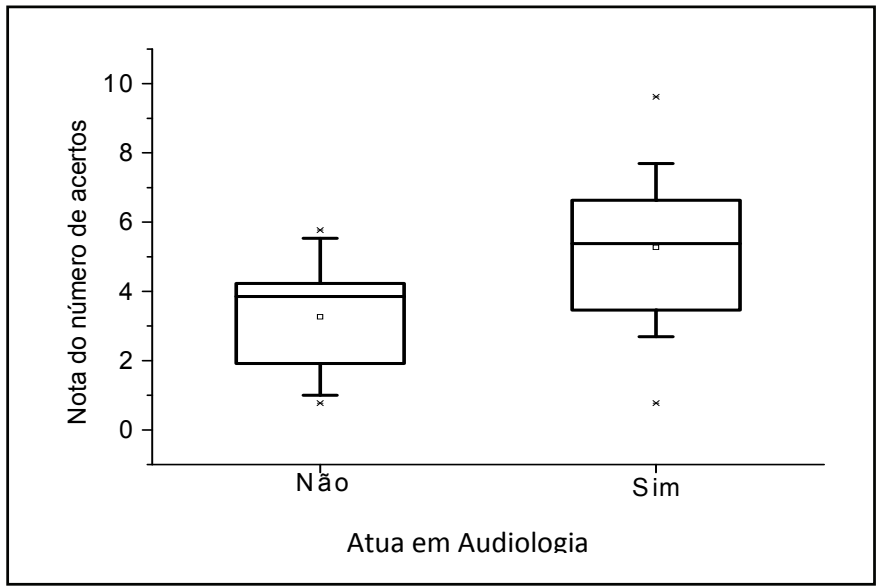

Figura 5 - Comparação entre o número total de acertos e os fonoaudiólogos pesquisados que atuam na área de audiologia

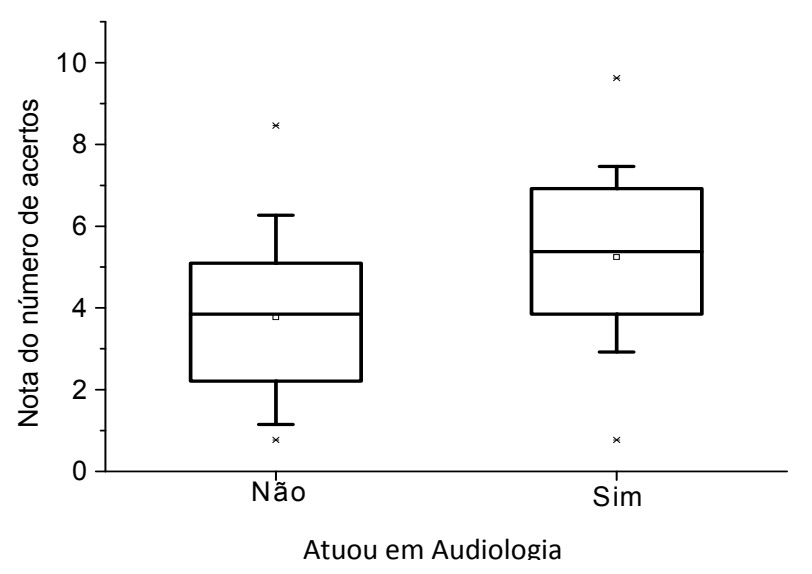

Figura 6 - Comparação entre o número total de acertos e os fonoaudiólogos pesquisados que atuaram na área de audiologia

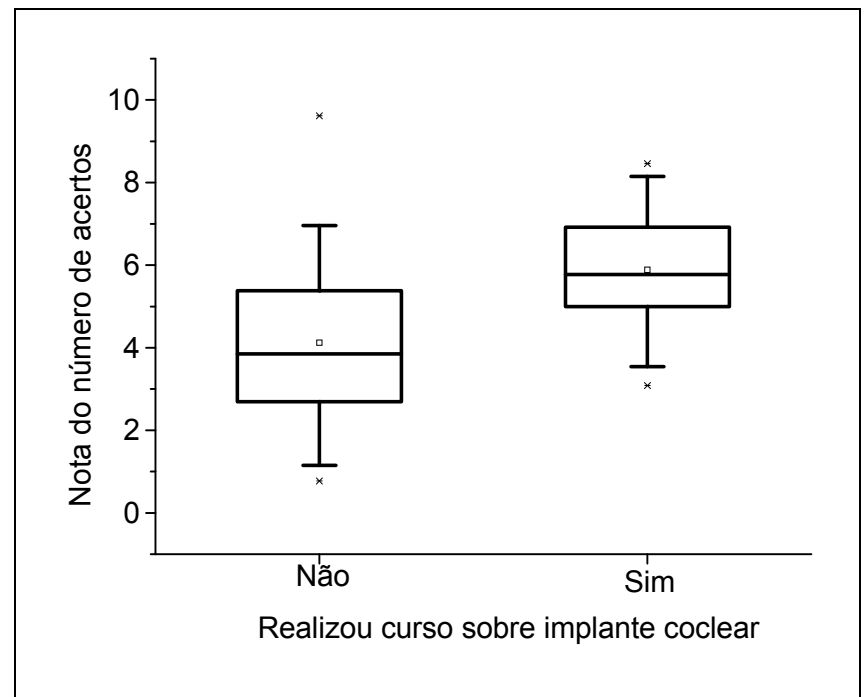

Figura 7 - Comparação entre o número total de acertos e os fonoaudiólogos pesquisados que realizaram curso sobre implante coclear 
informação sonora em sinais elétricos e levá-la diretamente ao nervo auditivo e, a partir deste, para o córtex temporal 1,3-8,10,12,16,17.

Os critérios necessários para a seleção dos candidatos (crianças, adolescentes e adultos) ao implante coclear também foi outra questão que gerou dúvidas, apesar de ser extremamente importante o conhecimento de tais pré-requisitos por parte dos profissionais fonoaudiólogos, visto que, para o atendimento de qualquer paciente implantado, em qualquer área da Fonoaudiologia, é necessário que o profissional saiba das condições auditivas do paciente e do caminho que esse, provavelmente, percorreu até o presente atendimento.

Diante disso, cabe ressaltar que o Ministério da Saúde, portaria no 1.278 , de 20 de outubro de 1999, preconiza alguns critérios necessários para a seleção do candidato ao implante coclear, sendo: o implante em crianças, menores de 18 anos com surdez pré e pós-lingual, dependendo de uma experiência prévia da criança com o uso de aparelho auditivo por, pelo menos, três meses; presença de incapacidade de reconhecimento de palavras, em conjunto fechado; sendo necessário que a família da criança esteja motivada, e que haja condições de realização da reabilitação auditiva na cidade de origem ${ }^{14}$.

É importante ressaltar que crianças com faixa etária acima de seis anos de idade e adolescentes devem ter realizado terapia fonoaudiológica desde o diagnóstico de perda auditiva, além de uso de aparelho auditivo. $O$ código linguístico estabelecido e motivação também se fazem necessários no caso de adolescentes ${ }^{18}$.

Para a realização do implante coclear em adultos, o Ministério da Saúde define ser necessário: presença de perda auditiva profunda bilateral e código linguístico estabelecido (surdez pós-lingual ou pré-lingual reabilitado oralmente); ausência de benefício com o uso de aparelho auditivo, além de adequação psicológica e motivacional. Outro fator a ser avaliado também na seleção dos candidatos ao implante coclear, é a importância de se obedecer a alguns critérios fisiológicos, como: o candidato ter um número mínimo de fibras auditivas remanescentes, capazes de fornecer sensações auditivas ${ }^{5,14}$.

O implante coclear está contra-indicado nos casos onde se observa: condições médicas ou psicológicas desfavoráveis, agenesia de cóclea, lesões centrais, infecção ativa da orelha média ou expectativa familiar aquém dos reais benefícios proporcionados pelo implante coclear ${ }^{8}$.

Todo candidato ao implante coclear deve submeter-se à avaliação de uma equipe interdisci- plinar que irá definir, de acordo com os achados, se o indivíduo está apto ou não a realizar a cirurgia ${ }^{13}$.

O tipo de perda auditiva, necessária para a indicação do implante coclear, foi uma das questões com maior frequência de respostas corretas, quanto ao grau de perda auditiva obteve-se uma homogeneidade de respostas corretas e incorretas. O implante coclear é indicado para perdas auditivas sensorioneurais profundas bilaterais. Atualmente, com os avanços tecnológicos, o implante coclear tem sido uma opção possível para perdas auditivas sensorioneurais bilaterais severas e, também, profundas com configuração descendente (os eletrodos são inseridos somente na região basal da cóclea). Os limiares auditivos nas frequências de $500 \mathrm{~Hz}, 1000 \mathrm{~Hz}$ e $2000 \mathrm{~Hz}$ devem estar em 90 decibéis ou intensidade maior, de acordo com os limiares considerados como padrão de normalidade ${ }^{7,18,19}$

Observou-se que o lado (orelha direita, esquerda ou ambas) em que o implante coclear deve ser inserido é outra questão que ainda não está bem definida para os fonoaudiólogos pesquisados devido a homogeneidade entre as respostas corretas e incorretas. Estudos realizados no Brasil revelam que o implante coclear é sempre unilateral $^{7,18}$. Portanto, por ser unilateral, indica-se o implante coclear na orelha com melhor resíduo auditivo e experiência com aparelho auditivo mais recentemente. Se ambas apresentarem resíduo auditivo, a inserção é realizada na pior orelha, enquanto que, se o desempenho de ambas for ruim, será indicado o implante para a melhor orelha, a que recebeu mais estimulação com o aparelho auditivo ou com perda auditiva recente ${ }^{7,18}$.

Um motivo, pelo qual se indica o implante coclear unilateral, é o fato de a colocação dos eletrodos na cóclea poder lesionar alguma estrutura coclear ou, até mesmo, eliminar o resíduo auditivo antes presente. Por isso, inserindo o implante coclear em apenas uma das orelhas, preserva-se a outra para novas tecnologias que possam surgir para reabilitar perdas auditivas de grande extensão ${ }^{12}$.

Subentende-se, de acordo com o Ministério da Saúde, portaria $n^{\circ} 1.278$, de 20 de outubro de 1999, que o implante coclear é implantado unilateralmente, pois tal portaria refere-se ao implante coclear como um único dispositivo, como unitário ${ }^{14}$.

Estudos iniciaram na América Latina sobre a colocação bilateral do implante coclear. A justificativa para esse método deve-se ao fato de a maioria dos implantados unilaterais apresentarem perda auditiva na orelha não-implantada e, também, por terem maior dificuldade na localização da fonte sonora. Assim, tiveram início os testes de implantação bilateral do implante coclear, em que 
se constataram as seguintes vantagens: melhor localização da fonte sonora, melhor discriminação da linguagem oral e aumento do prazer em ouvir música no modo estéreo. As desvantagens encontradas com esse método foram: maior custo (dois implantes cocleares), tempo de duração da cirurgia mais longo e menos pacientes implantados quando os critérios são limitados (somente pacientes pós-linguais, ou seja, que já tenham adquirido a linguagem oral) ${ }^{20}$.

Como ainda seguem os estudos sobre a colocação bilateral do implante coclear, a indicação padrão utilizada ainda é unilateralmente.

Nesta pesquisa, verificou-se que muitos profissionais desconhecem que passos devem seguir para ingressar na equipe que atua no implante coclear. Para que um fonoaudiólogo atue na equipe de implante, ele deve possuir, obviamente, graduação em Fonoaudiologia, além de, conforme o Ministério da Saúde, portaria no 1.278 , de 20 de outubro de 1999, uma formação específica por meio da realização de um curso de capacitação com 30 (trinta) horas teórico-clínicas, 30 (trinta horas) horas de mapeamento e 30 (trinta) horas de reabilitação ${ }^{14}$.

Quanto à atuação, o fonoaudiólogo participa da equipe básica de implante coclear. A presença e atuação do profissional fonoaudiólogo são extremamente relevantes em todas as etapas de indicação, avaliação, seleção e reabilitação do implante coclear, visto que esse processo só apresentará o resultado esperado se houver um atendimento fonoaudiológico especializado em todas essas etapas terapêuticas, ou seja, pré, peri e pós-operatórias ${ }^{8,10}$.

O profissional de Fonoaudiologia atua no período pré-cirúrgico como integrante da equipe examinadora, realiza a avaliação audiológica (audiometria tonal e vocal, medidas de imitância acústica, emissões otoacústicas, potencial evocado auditivo de tronco encefálico e testagem de apareIhos auditivos); também avalia a linguagem oral do candidato ao implante coclear, além de avaliar e esclarecer quanto às expectativas com o implante coclear. Tais ações são realizadas com o intuito de averiguar se os achados, tanto de audição quanto de linguagem oral, estão de acordo com os critérios para a indicação do candidato ao implante coclear. De um modo geral, a atuação do fonoaudiólogo na etapa pré-operatória se faz necessária para que o mesmo forneça o parecer fonoaudiológico do candidato ${ }^{7,10,18}$.

Durante a cirurgia, a presença do fonoaudiólogo é indispensável e sua atuação caracteriza-se pela realização da telemetria neural ou telemetria de resposta neural (verificação da resposta funcional do implante coclear) e pela verificação da impedância dos eletrodos implantados (investigação do funcionamento adequado dos eletrodos inseridos na cóclea). Esses procedimentos intraoperatórios permitem a verificação do funcionamento e nível de resposta do implante coclear, ainda durante a execução da cirurgia 10,13,19,21.

Após a cirurgia, o implantado ainda não é capaz de ouvir somente com o componente interno. $\mathrm{O}$ fonoaudiólogo atua no pós-operatório realizando a ativação dos eletrodos do dispositivo, bem como, o mapeamento, que ocorre de quatro a seis semanas após a realização da cirurgia, quando se inicia o período de reabilitação auditiva. O objetivo desses procedimentos é programar o processador de fala e ajustar o nível mínimo e máximo de estimulação em cada eletrodo do implante, a fim de promover, no indivíduo implantado, a sensação de audição. Em crianças, o mapeamento dos eletrodos e o balanceamento acontecem de dois em dois meses, no primeiro ano, de três em três meses, no segundo ano e anualmente após o segundo ano da realização da cirurgia. Em adultos, esses procedimentos são realizados de três em três meses, no primeiro ano, semestral, no segundo ano e anualmente após esse período. Outros exames como, audiometria em campo livre e testes de percepção de fala são também realizados no acompanhamento do paciente ${ }^{3,6,10,14}$.

Após a ativação do implante coclear, os sons percebidos, inicialmente, são distorcidos, fazendose necessário um treinamento com um fonoaudiólogo para que os sons possam ser identificados e codificados pelo cérebro e, aos poucos, o implantado aprenda a perceber esses novos estímulos elétricos e depois a codificar as mensagens sonoras. Devido a esse processo de treino, é fundamental que o implantado retorne periodicamente para atendimento com o fonoaudiólogo, realizando o ajuste dos eletrodos, treinamento das habilidades auditivas, leitura orofacial e aquisição da linguagem oral, no caso de crianças ${ }^{3,7,10}$.

Quando o implantado adquiriu a perda auditiva antes de desenvolver a fala (pré-lingual), é importante que também os familiares e professores participem ativamente do treino das habilidades introduzidas na terapia fonoaudiológica ${ }^{10}$.

A atuação da Fonoaudiologia no implante coclear é fundamental e se faz necessária em todas as etapas, desde a avaliação do candidato até a sua reabilitação. $O$ sucesso terapêutico desse processo depende do atendimento fonoaudiológico especializado. 


\section{CONCLUSÃO}

Esta pesquisa permitiu concluir que os fonoaudiólogos pesquisados, atuantes na cidade Porto Alegre/RS, não apresentam o conhecimento satisfatório sobre a atuação fonoaudiológica no implante coclear. Ainda surgem dúvidas, principalmente quanto à definição do implante coclear, sobre os candidatos à utilização, o lado de inserção desse dispositivo e a atuação fonoaudiológica no período pré, peri e pós-operatório (ativação dos eletrodos). Os fonoaudiólogos que apresentaram um pouco mais de conhecimento foram aqueles que atuaram ou atuam na área da audição (audiologia), ou haviam realizado curso de extensão, aperfeiçoamento ou especialização sobre implante coclear. Outro fator que se conclui, é que se faz relevante a instrução desses profissionais sobre a atuação fonoaudiológica no implante coclear, ainda no período de graduação, visando promover um conhecimento básico sobre o assunto.

\section{ABSTRACT}

Purpose: to assess the knowledge that speech therapists in Porto Alegre/RS have about speech therapy care as for the cochlear implant and explain through bibliographic review what the literature proposes as the competence of speech therapists in an interdisciplinary team for the cochlear implant. Method: 81 speech therapists working in Porto Alegre, RS, from any field of Speech Therpy, answered a questionnaire consisting of eighteen objective multiple-choice questions about the area(s) where they had worked or were working at the time, if they had been taught in college about speech therapy care as for the cochlear implant, or if they had taken any training program, extension or specialization courses about such device. They were also asked about the definition of cochlear implant, the criteria for prescribing it, the necessary qualification of a speech therapist to work in an interdisciplinary team for the cochlear implant, and what their work would be during the preoperative, perioperative and postoperative periods. Results: the interviewed professionals did not demonstrate adequate knowledge about the speech therapist's work in the cochlear implant team. The questions that accounted for the greatest number of complete or partial mistakes were the ones concerning cochlear implant candidates, implant side, and speech therapy care during preoperative, perioperative and postoperative periods (electrode activation). Conclusion: this research allowed us to conclude that the interviewed speech therapists in Porto Alegre did not have an adequate knowledge on speech therapy care in the cochlear implant.

KEYWORDS: Cochlear Implantation; Audiology; Health Knowledge, Attitudes, Practice; Professional Competence; Professional Practice

\section{REFERÊNCIAS}

1. Rizzi FML, Bevilacqua MC. Efeitos do número e localização dos eletrodos na cóclea na percepção da fala de indivíduos pós-linguais implantados. Rev Bras Otorrinolaringol. 2003; 69(3):364-9.

2. Bento RF, Neto RB, Castilho AM, Gómez VG, Giorgi SB, Guedes MC. Resultados auditivos com o implante coclear multicanal em pacientes submetidos a cirurgia no Hospital das Clínicas da Faculdade de Medicina da Universidade de São Paulo. Rev Bras Otorrinolaringol. 2004; 70(5):632-7.

3. Scaranello CA. Reabilitação auditiva pós-implante coclear. Medicina. 2005; 38(3/4):273-8.

4. Nasralla HR, Goffi V, Guedes MC, Peralta CGO. Implante coclear na adolescência: quatro candidatos, quatro percursos ao implante coclear. Arq Int Otorrinolaringol. 2008; 12(1):126-32.

5. Kozlowski L. Implantes cocleares. Carapicuíba: Pró-Fono; 1997.

6. Carvalho CN. Implante coclear no sul do Brasil: realidade ou fantasia? [monografia]. Porto Alegre (RS): CEFAC - Pós-Graduação em Saúde e Educação; 1999.

7. Oliveira JAA. Implante coclear. Medicina. 2005; 38(3/4):262-72.

8. Costa Filho OA, Bevilacqua MC. Implantes cocleares. In: Costa SS, Cruz OLM, Oliveira JAA, editores. Otorrinolaringologia: princípios e prática. 2. ed. Porto Alegre: Artmet; 2006. p. 447-53.

9. Bento RF, Neto RB, Sanchez TG. Complicações da cirurgia do implante coclear. Arq Int Otorrinolaringol. 2001; 5(3):158. 
10. Sleifer $P$, Lindner LB. Ouça o que eu falo: saiba mais sobre a sua audição. Porto Alegre: Corpore; 2003.

11. Goycolea M, Ribalta G, Levy R, Alarcón P. Implantes cocleares: conceptos generales. Rev Méd Clín Condes. 2003 Jan; 14(1): 48.

12. Gómez AC. Implante coclear. Acta Pediatr Mex. 2005 Mai-Jun; 26(3):111-2.

13. Costa OA, Bevilacqua MC, Nascimento LT. Implantes cocleares em crianças. In: Lavinsky L, organizador. Tratamento em otologia. Rio de Janeiro: Revinter; 2006. p. 478.

14. Brasil. Ministério da Saúde. Portaria N 1.278, de 20 de outubro de 1999.

15. Yamada MO, Bevilacqua MC. O papel do psicólogo no programa de implante coclear do Hospital de Reabilitação de Anomalias Craniofaciais. Estud Psicol. 2005; 22(3):255-62.

16. Villas Boas ACVB, Rodrigues OMPR, Yamada MO. Promovendo a interação mãe-criança com implante coclear: um estudo de caso. Psicol Teor Pesq. 2006; 22(3):259-68.
17. Stuchi RF, Nascimento LT, Bevilacqua MC, Brito Neto RV. Linguagem oral de crianças com cinco anos de uso do implante coclear. Pró-Fono. 2007; 19(2):167-76.

18. Gomez MVSG, Guedes MC, Sant'Anna SBG, Peralta CGO, Tsuji RK, Castilho AM, et al. Critério de seleção e avaliação médica e audiológica dos candidatos ao implante coclear: protocolo HC-FMUSP. Arq Int Otorrinolaringol. 2004; 8(4):295. 19. Guedes MC, Neto RVB, Gomez MVSG, Sant'Anna SBG, Peralta CGO, Castilho AM, et al. Telemetria de resposta neural intra-operatória em usuários de implante coclear. Rev Bras Otorrinolaringol. 2005; 71(5):660-7.

20. Montoya VR, Maldonado SG, Duarte JJ, Díaz FM, Zambrano CA. Implante coclear bilateral: reporte de un caso. Acta Otorrinolaringol Cir Cabeza Cuello. 2005 Mar; 33(1):4-9.

21. Sant'Anna SBG, Eichner ACO, Guedes MC. Benefício do implante coclear em indivíduos adultos com surdez pré-lingual. Mundo Saúde. 2008; 32(2):238-42.

DOI: 10.1590/S1516-18462010005000106

RECEBIDO EM: 21/09/2009

ACEITO EM: 23/12/2009

Endereço para correspondência:

Pricila Sleifer

Avenida Lavras 584/302

Porto Alegre - RS

CEP: $90460-040$

E-mail: pricilasleifer@uol.com.br 